\title{
The problem of screening children for visual defects
}

\author{
R. M. INGRAM \\ From the Kettering and District General Hospital
}

SUMMARY All the cases of squint and amblyopia referred to both hospital and school clinics in one district during one calendar year have been reviewed in order to clarify when, where, and how these cases first present to the ophthalmologist. The types of case at present seen in 'hospital' and 'school' clinics are quite different, and effective screening methods are unlikely to be developed if these two services continue to be regarded as separate entities. Exotropia is much less frequent than esotropia (only $15 \%$ of all cases of squint). The concept of a single peak number of first attendances of children with esotropia at age 3 to 4 years is not substantiated. There is a second peak at age 5 years, when children first go to school. In fact $49 \%$ first attended after their fifth birthday. The majority $(69 \%)$ of cases of amblyopia presented after the age of 5 years. Three-quarters of these $(46 \%$ of the total) have no clinically detectable squint. Neither they, nor those children who have a strabismic amblyopia, but not a cosmetically noticeable squint, will at present be detected until they have a sight test at school. This is a measure of the need to re-examine our long-established methods of screening children for amblyopia. One screening test designed to identify both the 'squinter' and the 'straight-eyed amblyope' is required.

Articles directly or indirectly criticising the 'late' discovery of children with squint and amblyopia appear regularly in the ophthalmic literature (e.g., Aaberg, 1968; Allen, 1967; Bettman and Fellows, 1961; Henderson, 1969; McNeil, 1955) and in other periodicals (e.g., McNeil, 1959; Miller, 1958; Nixseamann, 1970; Perkins, 1973). There is also the problem of non-strabismic amblyopia (e.g., Jampolski et al., 1955; Jackson, 1964; Phillips, 1959; Robinson, 1961; Sugar, 1944). Such cases usually escape detection until their visual acuity is tested, because there is no cosmetically obvious squint. Recently attention has turned towards the possibility of selecting children particularly at risk for squint, in the neonatal period (Seba, 1972) and later (Karpowicz, 1965; Kramar, 1973; Pratt-Johnson and Lunn, 1967).

Programmes to screen children for visual problems should be directed towards detecting just those cases that might be expected to respond to treatment at an age when this is still possible. Innovations should logically be based on a pattern of referrals and the results of treatment of those identified by methods currently in use. Adelstein and Scully (1967) reported the age at which children with squint were referred, but so far as I know there had been no comprehensive review to include also those cases found to have amblyopia, in the absence of a squint

Address for reprints: Dr R. M. Ingram, Kettering and District General Hospital, Rothwell Road, Kettering NN16 8UZ, Northants. detectable by the cover test, and defective vision associated with refractive errors (e.g., astigmatism and myopia) not usually associated with squint or ambiyopia. Fusion of the school eye service with the hospital service in this area (Ingram, 1973) provided the administrative and records facilities suitable for this study, which was designed to define the age of referral and mode of detection for the whole range of visual problems in one district during the period of one calendar year. Attention is drawn particularly to convergent squint and amblyopia.

\section{Sample of children}

Every child seen in the children's eye clinics at Kettering General Hospital and the Nuffield Diagnostic Centre at Corby during the period 1 November 1971 to 31 October 1972 was included. Ninety-one children were referred for what may be termed 'non-visual' problems. They have been excluded from the main part of the report; but they were investigated in the same manner as those with 'visual' problems because they might be representative of the population as a whole in some respects.

The main sample of the report comprises 665 children. All were referred by general practitioners, or as a result of a sight test at school with a provisional diagnosis of strabismus and/or visual defect. Collection of the sample continued for the period of one calendar year because Adelstein and Scully 
(1967) reported a seasonal incidence in the onset of squint and its referral.

Theoretically all cases of strabismus and/or amblyopia pass through an ophthalmologist's care at some stage. In this area they would pass through one of the two children's eye clinics mentioned above. Communications here are good between the children's eye clinic on the one hand and the general practitioners, opticians, and public health authorities on the other, and there are reasonable grounds for believing that nearly all the cases of strabismus or amblyopia detected during the year have been included in this survey. The drawing area of the 'general practitioner' and 'school' referrals can only be estimated and may not be quite the same. There is probably a slight excess of 'general practitioner' referrals (180000 population) over 'school' referrals (140 000 population). There might also be a slight deficiency of the $10+$ age group of children who have myopia, because some of these may have been seen by opticians without referral to hospital or school clinic. Apart from these two factors the sample presented here is probably representative of a general pattern of children found to have eye defects.

All the cases were 'new' in the sense that none of them had had any ophthalmic treatment or investigation anywhere before they were seen in this clinic.

\section{Methods}

The following information was recorded for each child:

(1) Source of referral.

(2) Age when first seen.

(3) Presence of strabismus detectable by the cover test. Children with an esophoria which breaks down on cover test to be an intermittent esotropia were recorded together with children who have a constant esotropia as 'esotropia'. It is accepted that microstrabismus is not detected by the cover test, which 'misses' deviations of less than two prism dioptres (Romano and von Noorden, 1971) and microtropia with identity.

(4) If manifest strabismus was diagnosed, the duration of the deviation was noted.

(5) Refraction (see Ingram, 1977).

(6) Presence of amblyopia. All visual acuities were measured on either a full Snellen chart or by using the linear Sheridan-Gardiner test. This eliminates the inaccuracies in vision testing if single letter charts are used (Hilton and Stanley 1972; von Noorden, 1970).

Visual acuity could not be recorded in a number of children, e.g., very nearly all those under the age of 3 years. A total of 59 cases have therefore been re- corded as ?amblyopia. Twenty-six of these were children under the age of 4 years who had esotropia which was not spontaneously alternating and in whom there were good grounds for believing that the deviating eye was amblyopic. It was not possible to obtain a visual acuity on the first attendance of the remaining 39 older children, and none of those kept a follow-up appointment to be seen after they had received their glasses (nine of these had a uniocular esotropia and 21 had a refractive error which we now know to be significantly associated with amblyopia, e.g., hypermetropia or anisometropia, and three other children had astigmatism).

(7) The family history was recorded as positive if there was a history of squint, 'cast', 'turn', or 'lazy eye' in mother, father, siblings, aunts, uncles, or cousins. A history of either parent or a sibling wearing glasses constantly was also recorded.

\section{Findings}

Table 1 Source of referral and diagnosis

\begin{tabular}{lcc}
\hline & G.P. referrals & School referrals \\
\cline { 2 - 3 } N.A.D. & 88 & 141 \\
Myopia & 1 & 144 \\
Squint & 96 & 64 \\
Hypermetropic anisometropia & 8 & 76 \\
Hypermetropic astigmatism & 0 & 13 \\
Hypermetropia & 9 & 10 \\
No refractive error or squint, & 0 & 15 \\
but amblyopia & 202 & 463 \\
\hline
\end{tabular}

Table 2 Pattern of referral of children with esotropia

\begin{tabular}{lcc}
\hline Age & G.P./Hospital & School \\
\hline 0 & 7 & - \\
1 & 11 & 1 \\
2 & 12 & 3 \\
3 & 23 & 1 \\
4 & 11 & 15 \\
5 & 9 & 12 \\
6 & 4 & 6 \\
7 & 3 & 15 \\
\hline+ & 4 & 53 \\
\hline
\end{tabular}

Table 3 Pattern of referral of cases of amblyopia or probable amblyopia

\begin{tabular}{lcc}
\hline Age & GP/Hospital & School \\
\hline 0 & 10 & - \\
1 & 11 & - \\
2 & 14 & - \\
3 & 16 & 1 \\
4 & 8 & 37 \\
5 & 4 & 26 \\
6 & 4 & 13 \\
7 & 2 & 44 \\
$8+$ & 4 & 123 \\
\hline
\end{tabular}




\section{Discussion}

The majority of children presenting with 'visual' problems were identified by the school or public health authorities suspecting some defect, the ratio of patients, school clinic to hospital clinic, being $2 \cdot 29: 1$ (Table 1). Strabismus was seen predominantly in the hospital clinic in a ratio of 1.5:1 (Table 2), but cases of amblyopia or ?amblyopia attended predominantly the school clinic in a ratio of $1.68: 1$ (Table 3). On the basis of these figures alone it seems illogical to have two separate services to treat strabismus and amblyopia. It does not really matter which clinic the children first attended; what is important is the age at which they presented.

There are two peak ages when children with esotropia presented, namely, 3 to 4 years and 5 to 6 years (Fig. 1). This is different from the picture presented by Adelstein and Scully (1967). The pattern for 'hospital' (i.e., general practitioner) referrals is very similar to the commonly held image, as presented in the 'hospital' cases of Adelstein and Scully's group (1967), but it is important to realise that $49 \%$ of the total were identified after the age of 5 , and these children do not usually attend a hospital clinic.

In this area general practitioners' cases are usually seen within two weeks of the possibility of squint being mentioned by the parents, and I feel that these $49 \%$ do not represent neglect on their part. Few have cosmetically noticeable deviations, and those that do seem to occur in 'problem' families. The majority, however, are small-angled deviations, not cosmetically noticeable, and they are diagnosed only when an ophthalmologist does a cover test. By contrast most of the preschool age cases of esotropia have a cosmetic defect which is readily noticeable.

The pattern of referral of amblyopia is demonstrated in Table 3 and Fig. 2, but the cardinal point is that $69 \%$ of amblyopic children were not identified until after they had gone to school. While $78 \%$ of the amblyopic children who presented before the age of 5 years had a clinically detectable esotropia, $75 \%$ of

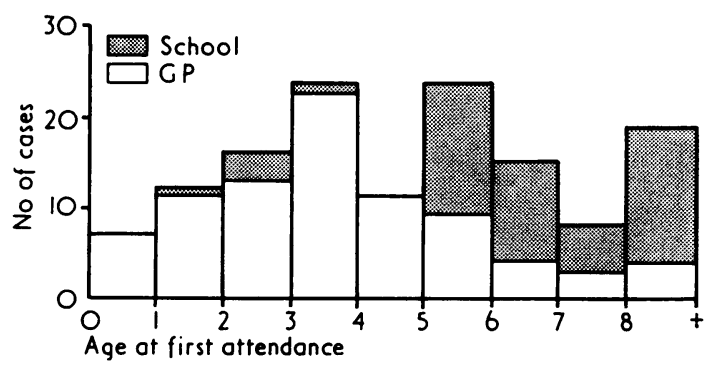

Fig. 1 Referral of cases of esotropia.

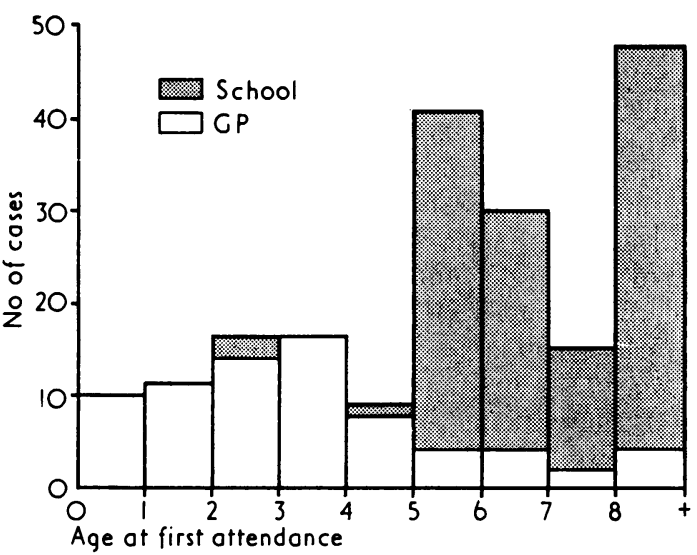

Fig. 2 Referral of amblyopia or? amblyopia.

those presenting with amblyopia after the age of 5 years had no such clinically detectable squint. These latter represent $46 \%$ of the total number of children found to have amblyopia.

It is predictable that the majority of cases of myopia will be seen in the school clinic; but $90 \%$ of the 'straight-eyed' anisometropes also presented this way. In respect of these two types of case the hospital and school clinics are quite different. Children with exotropia formed only $15 \%$ of the total number of cases of squint (24 out of 160 ), and as they presented a variable clinical pattern they have been excluded from further discussion.

\section{Screening: the problem}

Treatment of amblyopia associated with a manifest squint has to await the recognition of the cosmetic deformity of squint, but little more than $50 \%$ of children with esotropia have a cosmetically noticeable defect. On the other hand no improvement can be expected with either the 'straight-eyed' amblyopes or the child with a squint which is not cosmetically noticeable under the present system, unless either they have their visual acuity checked earlier than school entry or some totally different screening test is devised for use at an earlier age.

The current argument in favour of screening before school entry has been set out by Simons and Reinecke (1974). It implies subjective testing on 3 and 4-year-old children as has been advocated by Aaberg (1968), Allen (1957), Cashell (1969), Cholst et al. (1962), Costenbader and O'Neill (1968), Giles (1970), Jackson (1964), Perkins (1973), Press and Austin (1968), Rosenthal and von Noorden (1971), and possibly others. This method of screening has actually been tried by Amigo (1973), Cunningham (1959), Hufhines (1961), Hyams and Neumann 
(1972), Kohler and Stigmar (1973), Kaivonen and Kostenaja (1963), Nordlow and Joachimsson (1962), and Oliver and Nawratzki (1971), but it has never become established as a screening programme. Why? Possibly this is because any objective method, whether it be for visual acuity or anything else (e.g., stereopsis-Reinecke and Simons, 1974; Walraven, 1975), has the following disadvantages:

(a) It is time-consuming (and therefore expensive), and a number of children just do not respond-'untestability' (Lippmann, 1969).

(b) If the standard required for passing is harsh, then you get an excess of false positives, and if the standard required is low you 'miss' a number of defects (Kohler, 1973).

(c) A variable/low attendance for examination (Sutcliffe, 1960).

No method is likely to be perfect, but the first of these disadvantages could be overcome by employing a quick objective method of screening. Most of the 'straight-eyed amblyopes' have anisometropic refractive errors, and this must make one think seriously of refraction as an alternative to subjective testing in preschool children. It could be carried out before the age of 3 years, and if Kramar (1973) is correct with regard to the possibility of predicting strabismus, there is a possibility that we may screen, in one test, not only for non-strabismic amblyopia but also for strabismus and strabismic amblyopia as well. The only alternative is to use the family history as a guide to selecting children 'at risk'.

\section{References}

Aaberg, T. M. (1968). Journal of the Oklahoma Medical Association, 61, 143.

Adelstein, A. M., and Scully, J. (1967). British Medical Journal, 3, 334.

Allen, H. F. (1957). Pediatrics, 19, 1093.

Allen, H. F. (1967). A.M.A. Archives of Ophthalmology, 77, 1.

Amigo, G. (1973). British Journal of Ophthalmology, 57, 125.

Bettman, G. W., and Fellows, V. G. (1961). American Journal of Ophthalmology, 51, 339.

Cashell, G. T. W. (1969). Trans. Consilium Europaeum Strabismi Studio Deditum Congress, p. 86. London, Henry Kimpton.

Cholst, M. R., Cohen, I. J., and Losty, M. A. (1962). N.Y. State Journal of Medicine, 62, 3927.

Costenbader, F. D., and O'Neill, J. F. (1968). Sight Saving Review, 38, 135.
Cunningham, F. (1959). American Journal of Public Health, 49, 462.

Giles, C. L. (1970). Journal of Pediatrics, 77, 309.

Henderson, J. W. (1969). Journal of Pediatric Ophthalmology. $6,11$.

Hilton, A. F., and Stanley, J. C. (1972). British Journal of Ophthalmology, 56, 135.

Huf hines, D. M. (1961). Sight Saving Review, 31, 210.

Hyams, S. W., and Neumann, E. (1972). British Journal of Ophthalmology, 56, 572.

Ingram, R. M. (1973). British Medical Journal, 1, 278.

Ingram, R. M. (1977). British Journal of Ophthalmology, 61,

Jackson, C. R. S. (1964). British Orthoptic Journal, 21, 106.

Jampolski, A., et al. (1955). A.M.A. Archives of Ophthalmology, 54, 893.

Kaivonen, M., and Kostenaja, M. (1963), Acta Ophthalmologica, 41, 785.

Karkpwicz, S. (1965). Klinika Oczna, 35, 293.

Kohler, L. (1973). Acta Paediatrica Scandinavica, Suppl., 235.

Kohler, L., and Stigmar, G. (1973). Acta Paediatrica Scandinavica, 62, 17.

Kramar, P. O. (1973). British Orthoptic Journal, 30, 66.

Lippmann, O. (1969). A.M.A. Archives of Ophthalmology, 81, 763.

McNeil, N. L. (1955). British Journal of Ophthalmology, 39, 688.

McNeill, J. A. (1959). Minnesota Medicine, 42, 1084

Miller, S. J. H. (1958). The Practitioner, 181, 760.

Nixseamann, D. H. (1970). British Medical Journal, 2, 279.

von Noorden, G. K. (1970). A.M.A. Archives of Ophtha!mology, 84, 103.

Nordlow, W., and Joachimsson, S. (1962). Acta Ophthalmologica, 40, 453.

Oliver, M., and Nawratzki, I. (1971). British Journal of Ophthalmology, 55, 462.

Perkins, E. S. (1973). The Practitioner, 211, 171.

Phillips, C. I. (1959). British Journal of Ophthalmology, 43, 449.

Pratt-Johnson, J. A., and Lunn, C. T. (1967). Canadian Journal of Ophthalmology, 2, 50.

Press, E., and Austin, C. (1968). Journal of the American Medical Association, 204, 767.

Reinecke, R. D., and Simons, K. (1974). American Journal of Ophthalmology, 78, 714.

Robinson, J. (1961). British Orthoptic Journal, 18, 13.

Romano, P. E., and von Noorden, G. K. (1971). American Journal of Ophthalmology, 72, 10.

Rosanthal, A. R., and von Noorden, G. K. (1971). American Journal of Ophthalmology, 71, 873.

Seba, J. (1972). Ceskoslovenská Oftalmologie, 28, 120.

Simons, K., and Reinecke, R. D. (1974). American Journal of Ophthalmology, 78, 707.

Sugar, H. S. (1944). American Journal of Ophthalmology, 27, 469.

Sutcliffe, S. (1960). British Orthoptic Journal, 17, 1.

Walraven, J. (1975). American Journal of Ophthalmology, 80, 893. 